Article

\title{
Effects of Ferrous Sulfate Addition on the Selective Flotation of Scheelite over Calcite and Fluorite
}

\author{
Moon Young Jung ${ }^{1}$, Jay Hyun Park ${ }^{2, *}$ and Kyoungkeun Yoo ${ }^{3, *(1)}$ \\ 1 Department of Bio Environmental Engineering, Semyung University, 65 Semyung-ro, \\ Chungcheongbuk-do 27136, Korea; myjung@semyung.ac.kr \\ 2 Institute of Mine Reclamation Technology, Mine Reclamation Corporation(MIRECO), 2 Segye-ro, \\ Gangwon-do 26464, Korea \\ 3 Department of Energy \& Resources Engineering, Korea Maritime and Ocean University (KMOU), \\ 727 Taejong-ro, Busan 49112, Korea \\ * Correspondence: jayhp@mireco.or.kr (J.H.P.); kyoo@kmou.ac.kr (K.Y.)
}

Received: 15 September 2020; Accepted: 29 September 2020; Published: 30 September 2020

\begin{abstract}
The addition of ferrous sulfate as a depressant for Ca-bearing minerals such as calcite and fluorite during scheelite flotation was investigated to recover scheelite from tungsten mine tailings, using Hallimond-tube flotation tests, zeta-potential measurement and Fourier-transform infrared (FT-IR) analyses. The flotation tests indicate that the selectivity of scheelite recovery was the largest over calcite and fluorite under the following conditions: $0.5 \mathrm{~g}$ sample, $50 \mathrm{~g} / \mathrm{ton}$ AF65, $1 \times 10^{-3} \mathrm{M}$ sodium oleate, $1200 \mathrm{~g} /$ ton SF2 (sodium silicate and ferrous sulfate) depressant with the 8:2 ratio of sodium silicate and ferrous sulfate, $50 \mathrm{~mL} / \mathrm{min}$ air injection rate, $5 \mathrm{~min}$ flotation time, and $\mathrm{pH} 8$. The selectivity of scheelite flotation increased when the amount of SF2 depressant addition increased to $1200 \mathrm{~g} /$ ton, but it decreased by adding $1400 \mathrm{~g} /$ ton SF2, which would result from the precipitation of iron components. In the zeta potential results, the zeta potentials of scheelite with the collector show similar results regardless of the addition of SF2, while the change of zeta potentials of calcite and fluorite by adding $\mathrm{NaO}$ collector diminished when SF2 was added. In FT-IR analyses, the spectrum of $\mathrm{NaO}$ in scheelite results was observed regardless of the addition of SF2, while the spectra of $\mathrm{NaO}$ in calcite and fluorite results disappeared when SF2 was added. These results suggest that the addition of SF2 prevents the adsorption of $\mathrm{NaO}$ on the surface of calcite and fluorite. Therefore, the addition of SF2 could enhance the selectivity of scheelite flotation over calcite and fluorite.
\end{abstract}

Keywords: scheelite; calcite; fluorite; depressant; ferrous sulfate; selective flotation

\section{Introduction}

The number of abandoned metal mines in South Korea has been found to be 2089, and it was reported that 1268 of the abandoned metal mines have detrimentally affected the environments around the abandoned mines [1]. Sangdong mine is a representative scheelite mine in South Korea, and 12 million tons of tailings was generated during a 40-year operation after it had been abandoned [2,3]. In South Korea, Mine Reclamation Corporation (MIRECO), a state-owned company, has developed technologies to recover valuable materials from tailings [4], which could reduce potential risk of tailings. Although some research was performed to use the tailing of Sandong mine as constructive materials [2], technology for the recovery of valuable materials such as scheelite should be required.

Scheelite has been found to be a representative tungsten ore [5]. Tungsten is being widely used in various industries such as the high-temperature technology, chemical, lighting, $\mathrm{X}$-ray technology, and machine manufacturing industries, owing to its low vapor pressure, high melting point, excellent electricity and thermal conductivity, high density, high abrasion resistance, and excellent 
X-ray performance [6,7]. Therefore, the recovery of scheelite from tailings is important not only in obtaining tungsten, but also in reducing the volume of tailings. Gravity separation such as jig process has been reported to recover scheelite [8], but, generally, the flotation process has been selected for beneficiation of scheelite [9].

It is known that scheelite can be selectively floated by using fatty acid and a fatty acid derivative as a collector $[10,11]$. However, since scheelite $\left(\mathrm{CaWO}_{4}\right)$ contains calcium components, it is closely related to other Ca-bearing minerals such as calcite $\left(\mathrm{CaCO}_{3}\right)$ and fluorite $\left(\mathrm{CaF}_{2}\right)$. Scheelite has similar physicochemical properties, such as the existence of the same cations $\left(\mathrm{Ca}^{2+}\right)$ in the mineral, solubility, hardness, specific gravity, and point of zero charge [12,13], which causes similar chemisorption behavior of the fatty acid and a fatty acid derivative as a collector on the Ca-bearing minerals [9,14-16]. Generally, it has been found that sodium silicate is the most widely used depressant for selective flotation of scheelite [15], and assistant depressant such as ferrous sulfate has been investigated [15,16].

Although the mechanism of the depression of calcite [15] and fluorite [16] during scheelite flotation, using a mixture of sodium silicate and ferrous sulfate as a depressant, was reported by investigating the minerals with X-ray photoelectron spectroscopy (XPS), more experiments will be required to understand the depression mechanism of sodium silicate and ferrous sulfate. Therefore, in the present study, the optimum flotation condition was obtained from Hallimond-tubes flotation tests, and then the effect of ferrous sulfate addition with sodium silicate was investigated with zeta potential measurement and FT-IR analyses using scheelite, calcite and fluorite conditioned at the optimum condition.

\section{Materials and Methods}

\subsection{Materials}

The samples that were used in this study were the concentrates of scheelite $\left(\mathrm{CaWO}_{4}\right)$, calcite $\left(\mathrm{CaCO}_{3}\right)$, and fluorite $\left(\mathrm{CaF}_{2}\right)$, which were obtained from domestic mines such as Sandong mine, Imha mine, and Sinpo mine, respectively. Figure 1 shows the X-ray diffraction (XRD) analysis results for scheelite, calcite, and fluorite. The analysis results show that all the three samples are pure, with almost absolutely no impurities.

All reagents used in this study are of reagent grade except AF65 (commercial grade). Sodium oleate (Samchun Chemical Co., Ltd., Yeosu, Korea), which is known to be used often in the flotation research on scheelite and Ca-bearing minerals [15,16], and AF65 (Cytec Industries Inc., Woodland Park, NJ, USA) were used as a collector and a frother, respectively. A mixture of ferrous sulfate heptahydrate $\left(\mathrm{FeSO}_{4} \cdot 7 \mathrm{H}_{2} \mathrm{O}\right.$, Samchun Chemical Co., Ltd., Yeosu, Korea), or oxalic acid $\left(\mathrm{C}_{2} \mathrm{H}_{2} \mathrm{O}_{4} \cdot 2 \mathrm{H}_{2} \mathrm{O}\right.$, Samchun Chemical Co., Ltd., Yeosu, Korea) with sodium silicate $\left(\mathrm{Na}_{2} \mathrm{SiO}_{3}\right.$, Samchun Chemical Co., Ltd., Yeosu, Korea) was used as a depressant. Table 1 shows the summary of the depressant used in this study.

Table 1. Depressants used in this study.

\begin{tabular}{ccc}
\hline Depressant & Abbreviation & Chemical Composition \\
\hline Sodium silicate & & $\mathrm{Na}_{2} \mathrm{SiO}_{3}$ \\
Sodium silicate + ferrous sulfate & $\mathrm{SF} 2$ & $\mathrm{Na}_{2} \mathrm{SiO}_{3}+\mathrm{FeSO}_{4}$ \\
Sodium silicate + oxalic acid & $\mathrm{SO}$ & $\mathrm{Na}_{2} \mathrm{SiO}_{3}+\mathrm{C}_{2} \mathrm{H}_{2} \mathrm{O}_{4}$ \\
\hline
\end{tabular}



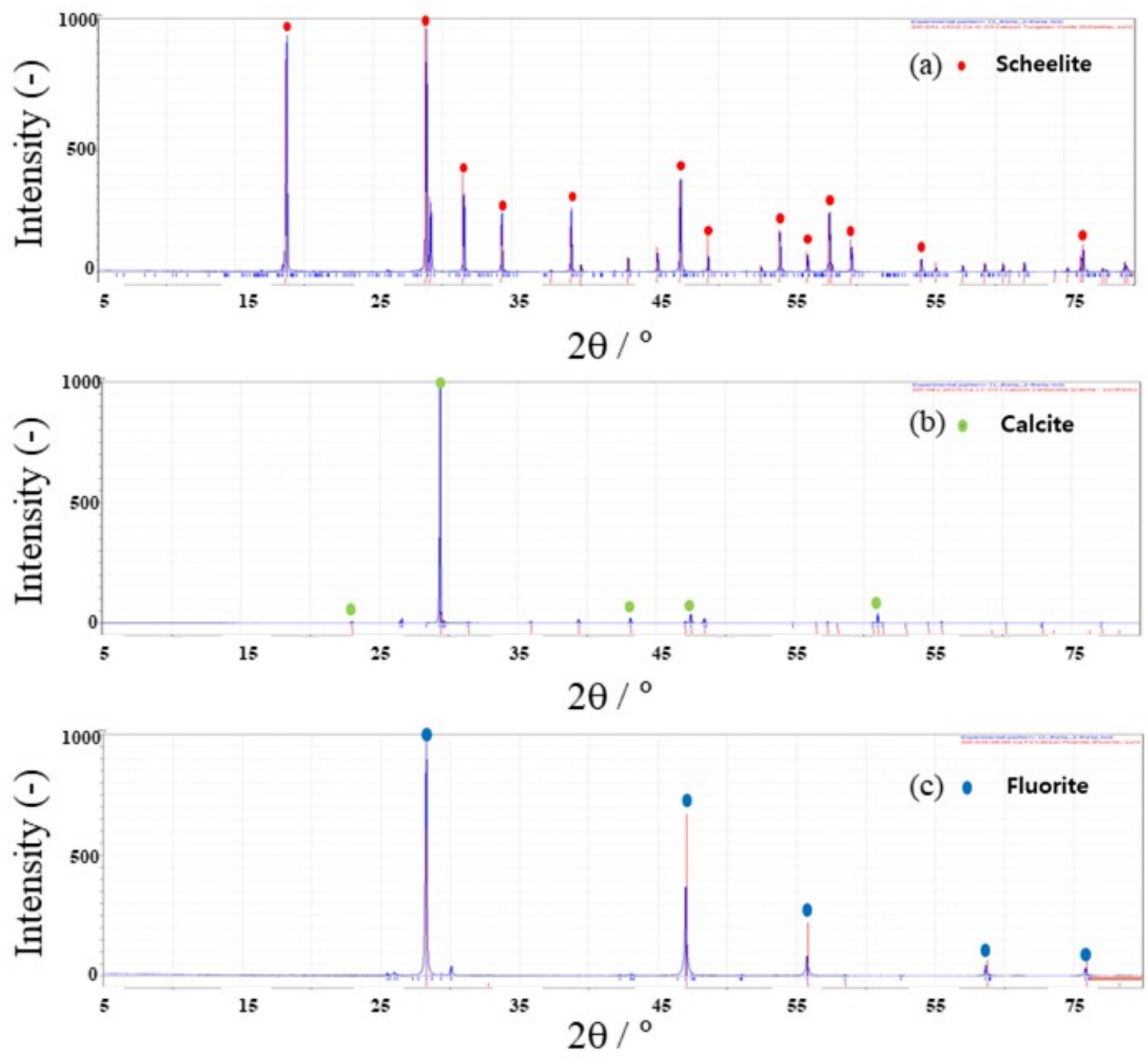

Figure 1. X-ray diffraction (XRD) analysis results for Ca-bearing minerals: (a) scheelite $\left(\mathrm{CaWO}_{4}\right)$, (b) calcite $\left(\mathrm{CaCO}_{3}\right)$, and (c) fluorite $\left(\mathrm{CaF}_{2}\right)$.

\subsection{Flotation Test Procedures}

Flotation tests on singular mineral (scheelite, calcite, and fluorite) were using Hallimond tubes with $300 \mathrm{~mL}$ of working volume under the following conditions: $0.5 \mathrm{~g}$ mineral sample $(75 \mu \mathrm{m}-150 \mu \mathrm{m})$, $50 \mathrm{~g} /$ ton AF65 as a frother, $1 \times 10^{-3} \mathrm{M}$ sodium oleate as a collector, $50 \mathrm{~mL} / \mathrm{min}$ air injection rate, 5 -min conditioning for each reagent addition, and $5 \mathrm{~min}$ flotation time. The pulp was stirred with a magnetic bar during the conditioning and flotation tests. In a typical run, the $\mathrm{pH}$ of $300 \mathrm{~mL}$ distilled water with the sample was adjusted at 8 with $\mathrm{HCl}$ and $\mathrm{NaOH}$, and then depressant, collector, and frother were added in order. After the flotation tests, the products were collected by filtering with a filter paper and then dried at $105{ }^{\circ} \mathrm{C}$. The floatability (\%) was calculated as follows:

$$
\text { Floatability }(\%)=\mathrm{M}_{\text {final }}(\mathrm{g}) / \mathrm{M}_{\text {initial }}(\mathrm{g}) \times 100
$$

where $\mathrm{M}_{\text {final }}$ and $\mathrm{M}_{\text {initial }}$ indicate mass of final and initial added mineral, respectively.

\subsection{Zeta Potential and Fourier-Transform Infrared (FTIR) Analyses}

The zeta potentials of the mineral particles were measured with Beckman Coulter's Delsa Nano C. The mineral samples were finely ground with an agate mortar, and less than $5 \mu \mathrm{m}$ particles collected using a filter (pore size: $5 \mu \mathrm{m}$ ) were used. The zeta potential was measured using a $1.0 \times 10^{-3} \mathrm{M}$ 
$\mathrm{NaCl}$ solution as the supporting electrolyte. The $\mathrm{pH}$ value was adjusted with $\mathrm{HCl}$ and $\mathrm{NaOH}$ and was measured after the Zeta potential tests.

The adsorption of the collector and depressants on the surfaces of Ca-bearing minerals was examined using Jasco's FTIR spectrometer. After the $0.5 \mathrm{~g}$ mineral sample with less than 200 mesh was added to $300 \mathrm{~mL}$ distilled water, the flotation reagents (collector and depressant) were added to the suspension, which was conditioned for $5 \mathrm{~min}$. Then, the solid-liquid separated mineral samples were dried in vacuum before FTIR analyses.

\section{Results and Discussion}

Bo et al. reported that sodium silicate forms hydrophilic colloidal silicic acid, which is selectively adsorbed on the surface of calcite and fluorite, and that, in particular, the formation of hydrophilic colloids became smoother in their study when the mixing ratio of sodium silicate and oxalic acid was 3:1 [17]. Based on this finding, the depressant that contains the sodium silicate and oxalic acid in a ratio of 7.5:2.5, 5:5, 2.5:7.5, and 0:10 was used to investigate the effect of the depressants on the floatability of scheelite, calcite and fluorite. Figure 2 shows the floatability of the minerals increased, but the selectivity decreased with decreasing the ratio of sodium silicate.

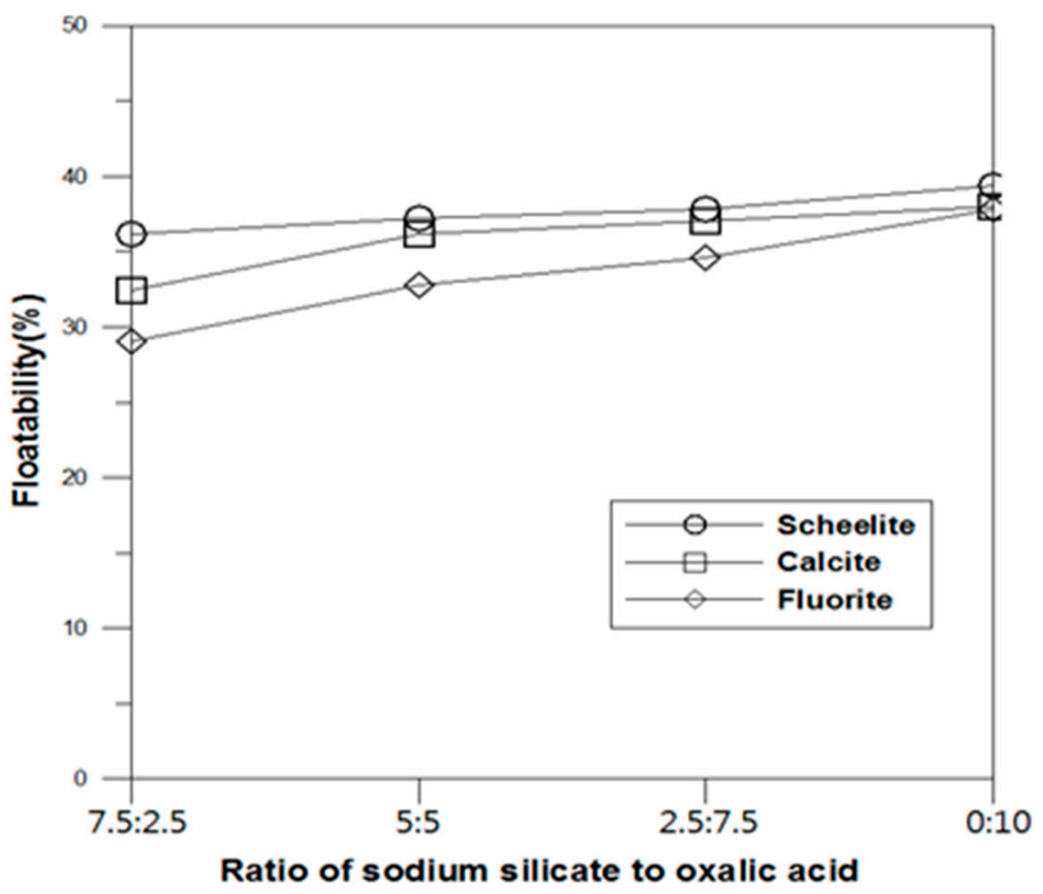

Figure 2. Floatability of scheelite, calcite, and fluorite in the function of the mixing ratio of sodium silicate and oxalic acid from 7.5:2.5 to 0:10.

The difference in floatability was the highest at the 7.5:2.5 sodium silicate-oxalic acid mixing ratio, and the result shows a good agreement with the conventional study [17], where the 3:1 ratio was suggested as an optimum condition. At this ratio of 7.5:2.5, however, the floatabilities of scheelite, calcite and fluorite were $36 \%, 32 \%$ and $29 \%$, respectively. Thus, satisfactory selection efficiency could not be expected when using the depressant of sodium silicate and oxalic acid.

The combination of sodium silicate and ferrous sulfate (SF2) was proposed as a depressant for the selective flotation of scheelite $[15,16]$. The depressant SF2 was prepared in a ratio of 6:4 to 9:1 of $5 \%$ sodium silicate and 1\% ferrous sulfate. The flotation tests with SF2 were performed under the following conditions: $0.5 \mathrm{~g}$ sample, $50 \mathrm{~g} /$ ton AF65, $1 \times 10^{-3} \mathrm{M}$ sodium oleate, $200 \mathrm{~g} / \mathrm{ton} \mathrm{SF} 2 \mathrm{depressant,}$ $50 \mathrm{~mL} / \mathrm{min}$ air injection rate, $5 \mathrm{~min}$ flotation time, and $\mathrm{pH} \mathrm{8,} \mathrm{and} \mathrm{the} \mathrm{results} \mathrm{are} \mathrm{shown} \mathrm{in} \mathrm{Figure} 3$. 


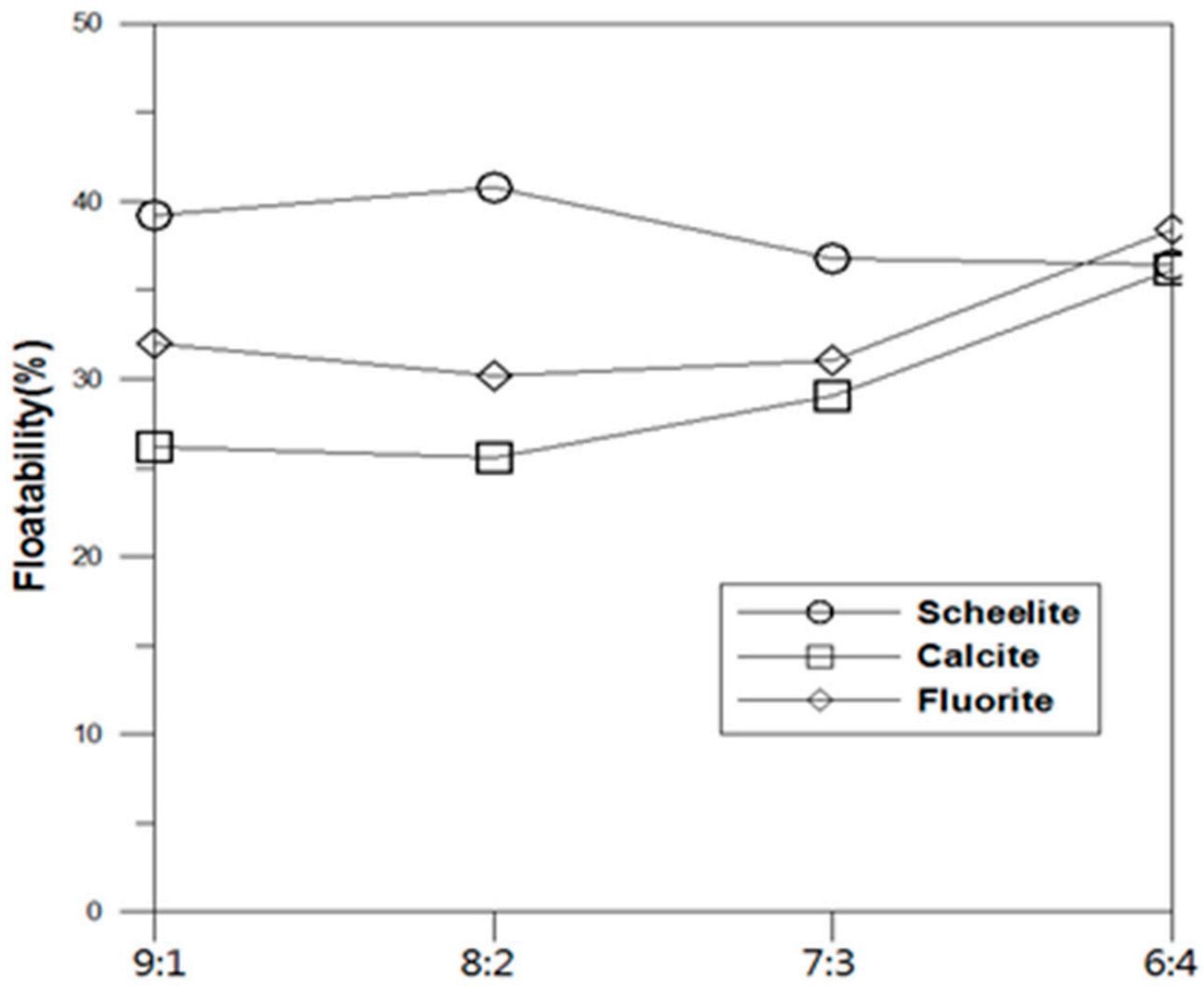

Ratio of sodium silicate to ferrous sulfate

Figure 3. Floatability of scheelite, calcite, and fluorite in the function of the mixing ratio of sodium silicate and ferrous sulfate from 6:4 to 9:1.

The floatability of scheelite decreased but those of calcite and fluorite increased with increasing the ratio of ferrous sulfate. The precipitation was observed in the solution, and the amount of precipitate increased with the ratio of ferrous sulfate. Iron component was detected in the precipitate, and iron precipitated due to the oxidation of ferrous to ferric ions by aeration because ferric ion could precipitate over $\mathrm{pH} 3.5$ [18]. At a ratio of 8:2 for sodium silicate and ferrous sulfate, the floatabilities of scheelite, calcite and fluorite were $40.8 \%, 25.6 \%$ and $30.2 \%$, respectively, and the selectivity was the largest at this ratio. The selectivity decreased with increasing the ratio of ferrous sulfate because the effect of ferrous sulfate addition diminished due to the precipitation.

The effects of SF2 depressant dosage on the floatability of scheelite, calcite, and fluorite was investigated under the following conditions: $0.5 \mathrm{~g}$ sample, $50 \mathrm{~g} / \mathrm{ton} \mathrm{AF} 65,1 \times 10^{-3} \mathrm{M}$ sodium oleate, 0-1400 $\mathrm{g} /$ ton SF2 depressant with the $8: 2$ ratio of sodium silicate and ferrous sulfate, $50 \mathrm{~mL} / \mathrm{min}$ air injection rate, 5 min flotation time, and $\mathrm{pH} 8$, and the results were shown in Figure 4. With increasing SF2 dosage, the floatability of scheelite decreased gradually while those of calcite and fluorite did sharply. That is, when the SF2 dosage increased from 200 to $1200 \mathrm{~g} /$ ton, the floatability of scheelite decreased by $7 \%$ (from 40.8 to $33.6 \%$ ) but the floatability of calcite decreased sharply by $21 \%$ (from 25.6 to $4.6 \%$ ) and that of fluorite decreased sharply by approximately $20 \%$ (from 30.2 to $10.6 \%$ ). When the SF2 dosage was $1400 \mathrm{~g} /$ ton, the floatability values of calcite and fluorite were around 5\%, suggesting an excellent suppressing effect, but that of scheelite was also severely suppressed to around $20 \%$. Since the selectivity is the largest at $1200 \mathrm{~g} / \mathrm{ton}$ of SF2 dosage, the SF2 dosage was fixed at $1200 \mathrm{~g} / \mathrm{ton}$ in the following tests. 


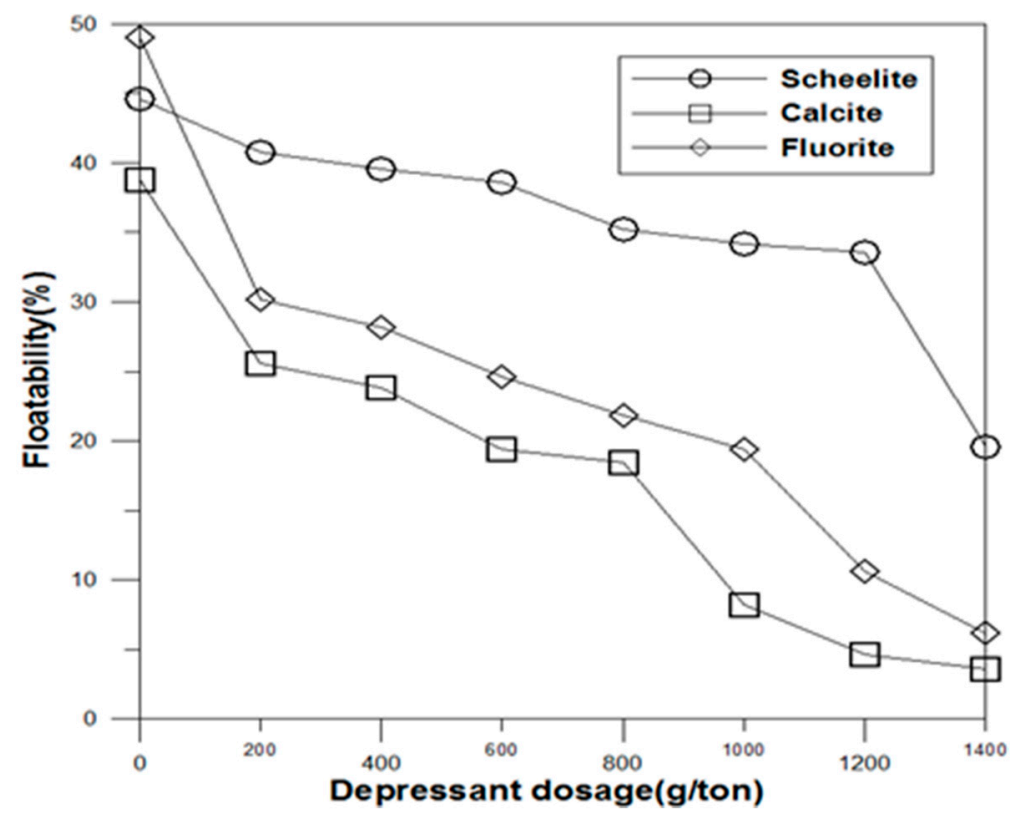

Figure 4. Floatability of scheelite, calcite, and fluorite in the function of SF2 dosage.

The generally known order of addition of flotation reagents is to add a depressant before a collector. The Ca-bearing minerals were recovered through bulk flotation using the collector sodium oleate, and then selective flotation was performed for scheelite from the bulk flotation product. Therefore, the effect of the order of flotation-reagent addition on the floatability was investigated under the following conditions: $0.5 \mathrm{~g}$ sample, $50 \mathrm{~g} / \mathrm{ton}$ AF65, $1 \times 10^{-3} \mathrm{M}$ sodium oleate, $1200 \mathrm{~g} / \mathrm{ton}$ SF2 depressant with the $8: 2$ ratio of sodium silicate and ferrous sulfate, $50 \mathrm{~mL} / \mathrm{min}$ air injection rate, 5 min flotation time, and $\mathrm{pH}$ 8. The results are shown in Figure 5.

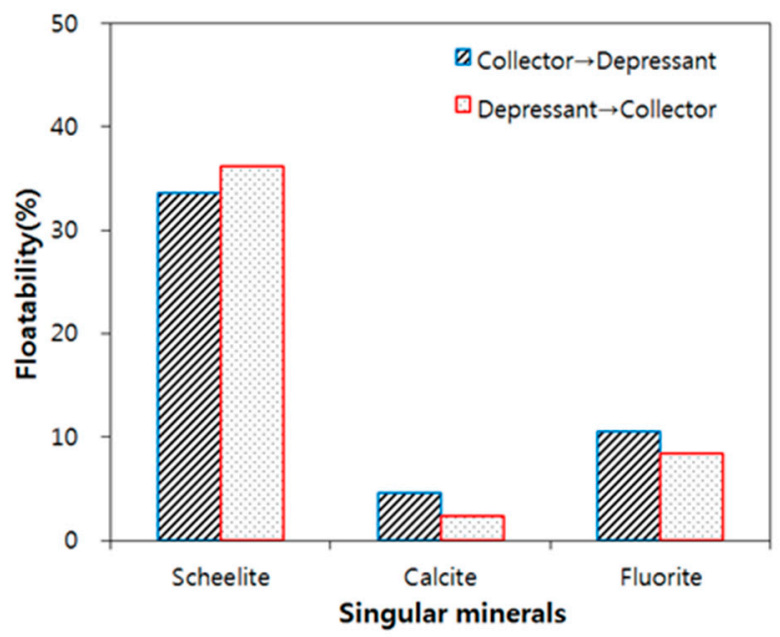

Figure 5. Floatability of scheelite, calcite, and fluorite in the function of the order of flotation-reagent addition.

As shown in Figure 5, the floatability of scheelite was higher than those of calcite and fluorite. The floatability of calcite and fluorite reduced when the depressant was added before the collector, while that of scheelite was enhanced by adding the depressant before the collector, where the selectivity became larger. Therefore, the effect of collector, which was added in the bulk flotation, should be considered to obtain the better selectivity of scheelite. Based on the results, the optimum flotation conditions with high selection efficiency for scheelite are $0.5 \mathrm{~g}$ sample, $50 \mathrm{~g} /$ ton AF65, $1 \times 10^{-3} \mathrm{M}$ sodium oleate, $1200 \mathrm{~g} /$ ton SF2 depressant with the 8:2 ratio of sodium silicate and ferrous sulfate, 
$50 \mathrm{~mL} / \mathrm{min}$ air injection rate, $5 \mathrm{~min}$ flotation time, and $\mathrm{pH} 8$, and the addition order of flotation reagents is to add the depressant before the collector.

Figures 6-8 show the zeta potential measurement results for scheelite, calcite, and fluorite with or without $1 \times 10^{-3} \mathrm{M}$ sodium oleate (collector) and $1200 \mathrm{~g} /$ ton SF2 (depressant). Each measurement was performed after $5 \mathrm{~min}$ conditioning when the collector or the depressant was added, and $1 \times 10^{-3} \mathrm{M}$ $\mathrm{NaCl}$ was added as a supporting solution. In the zeta potentials of scheelite, calcite, and fluorite without the collector and depressant, the measurement results showed that scheelite did not have a point of zero charge (PZC), but that the points of zero charge for calcite and fluorite are 8.6 and 4.7, respectively. Figure 6 indicates the Zeta potential results of scheelite with $\mathrm{pH}$, which shows a good agreement with conventional studies $[14,19]$. The zeta potentials of scheelite without the collector and depressant are negatively charged over the entire $\mathrm{pH}$ range (2-11), and the zeta potentials are lower negatively when the flotation reagents are added. Since the zeta potentials of scheelite with the collector or with the collector and depressant show similar behaviors over the entire $\mathrm{pH}$ range, the addition of depressant does not have a significant effect on the adsorption of the collector on the surface of scheelite.

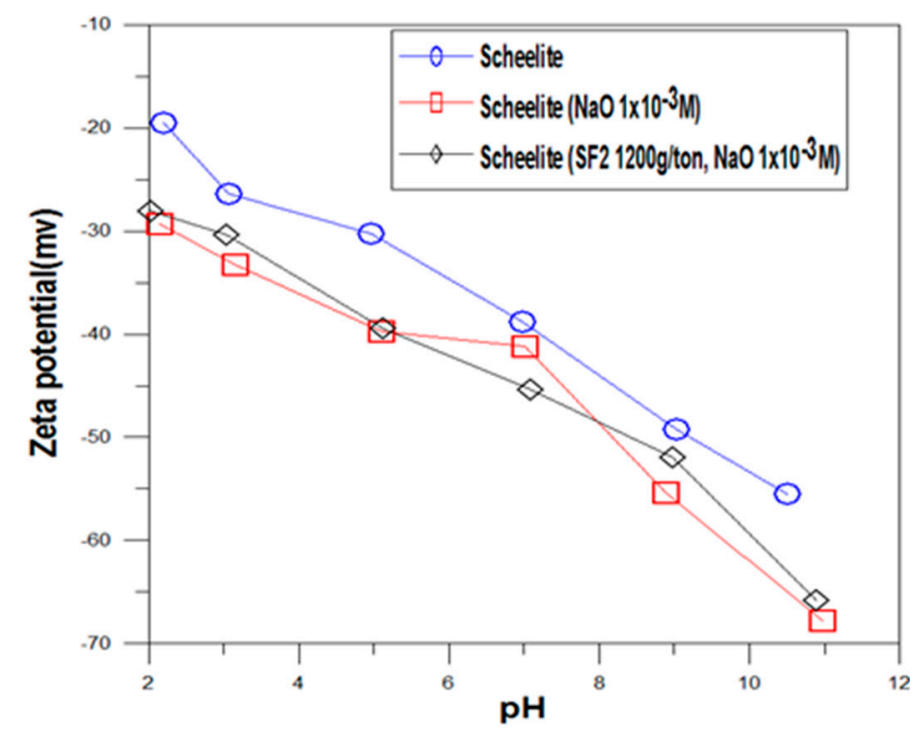

Figure 6. Zeta potentials of scheelite with and without the collector and depressant.

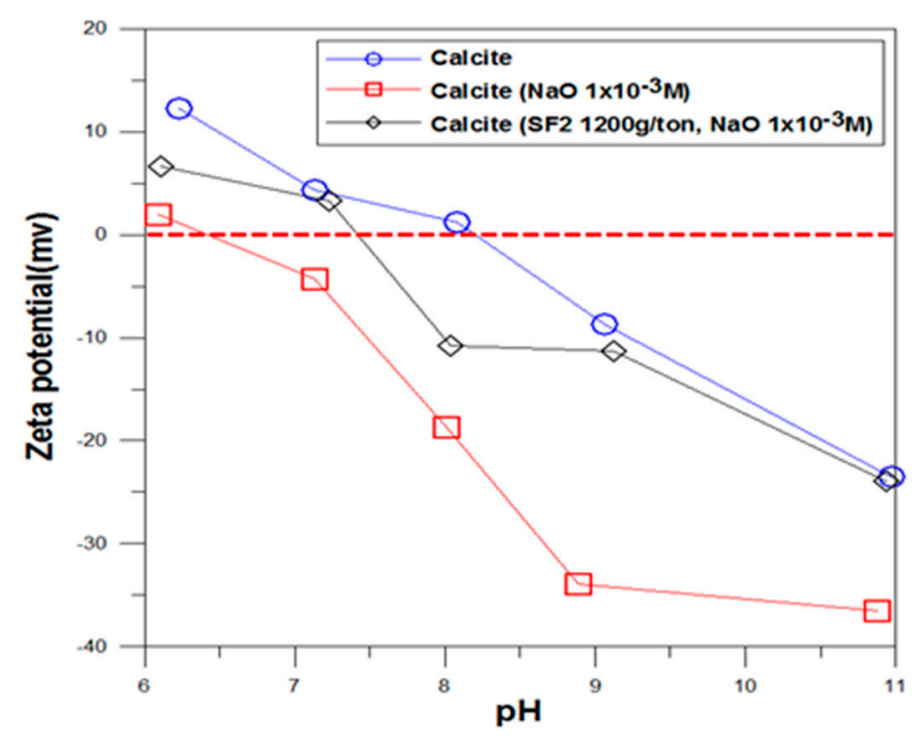

Figure 7. Zeta potentials of calcite with and without the collector and depressant. 


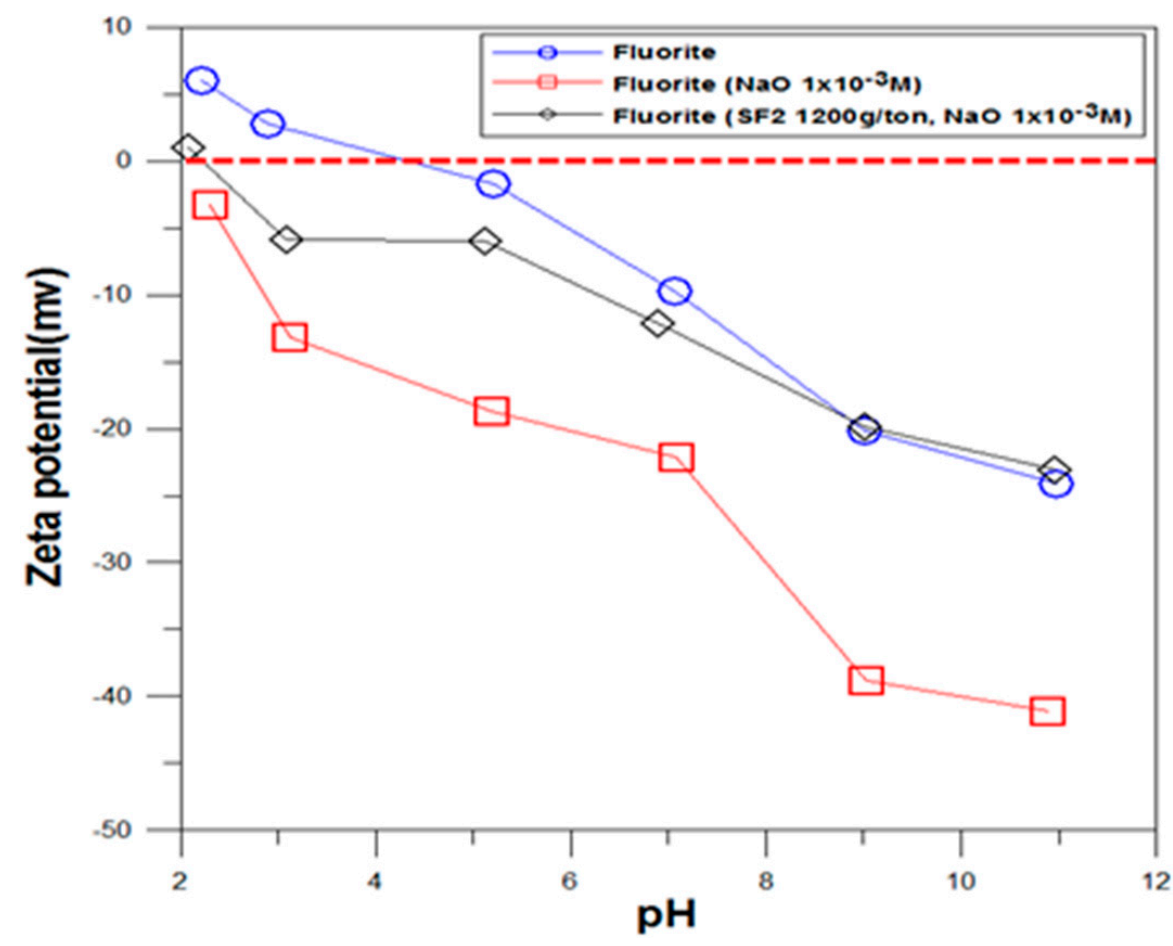

Figure 8. Zeta potentials of fluorite with and without the collector and depressant.

As shown in Figures 7 and 8, the zeta potentials of the calcite and fluorite only with the collector are the lowest at each $\mathrm{pH}$ compared with the zeta potentials of the minerals with or without the collector and depressant. The zeta potentials of calcite and fluorite with or without the collector and depressant show similar behaviors with increasing $\mathrm{pH}$, which indicates that the addition of the SF2 depressant interfered the adsorption of the collector on the surface of minerals. Therefore, the addition of SF2 could enhance the selectivity of scheelite flotation.

FTIR analysis was performed to examine the adsorption of the flotation reagents on the surface of the minerals conditioned at the optimum flotation conditions, and the results were shown in Figures 9-11 for scheelite, calcite, and fluorite, respectively. Figure 9 shows the FTIR analysis results for scheelite, where the spectrum of sodium oleate forms the bands at 1559.1 and $2922.6 \mathrm{~cm}^{-1}$. The band at $2922.6 \mathrm{~cm}^{-1}$ is known to be formed by the stretching vibrations of $\mathrm{CH}_{2}$ and $\mathrm{CH}_{3}$ [17], and the band at $1559.1 \mathrm{~cm}^{-1}$ is caused by the carbonyl mode $(\mathrm{C}=\mathrm{O})$, which mainly indicates a physically adsorbed species $[7,20,21]$. The spectrum of scheelite without flotation reagents (NaO and SF2) shows the bands in the 650-1000 $\mathrm{cm}^{-1}$ range, and, when the scheelite sample was conditioned in the $1 \times 10^{-3} \mathrm{M}$ sodium oleate solution, a band was observed at $2871.3 \mathrm{~cm}^{-1}$, which is similar to the $2922.6 \mathrm{~cm}^{-1}$ of sodium oleate. In the experiment where the SF2 depressant was added before sodium oleate, a band was formed at $2900.7 \mathrm{~cm}^{-1}$. These results suggest that the chemisorption of sodium oleate on the scheelite is maintained regardless of the addition of SF2. However, in the cases of calcite and fluorite, as shown in Figures 10 and 11, respectively, the spectra of calcite and fluorite with the collector $(\mathrm{NaO})$ show the band at 2931.5 and $2910.4 \mathrm{~cm}^{-1}$, which are due to the stretching vibration of sodium oleate, indicating good adsorption, but they disappeared in the minerals with the collector after the addition of the depressant (SF2). These results indicate that the addition of SF2 depressant prevents the adsorption of the $\mathrm{NaO}$ collector, which shows a good agreement with the experiment results of zeta potential measurement. Therefore, the addition of SF2 depressant could enhance the selectivity of scheelite over Ca-bearing minerals such as calcite and fluorite. 


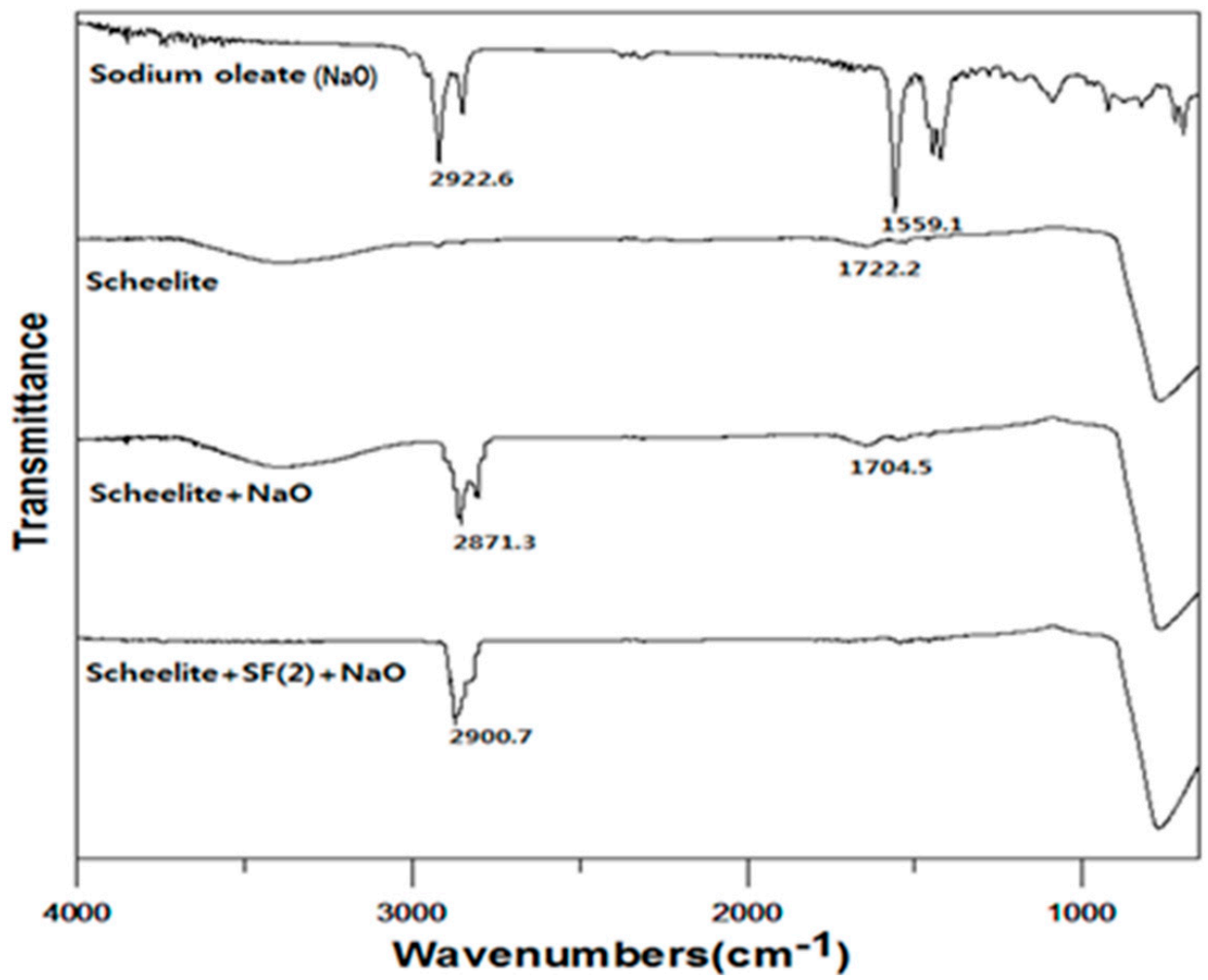

Figure 9. Fourier-Transform Infrared (FTIR) analysis result of scheelite at the optimum flotation conditions.

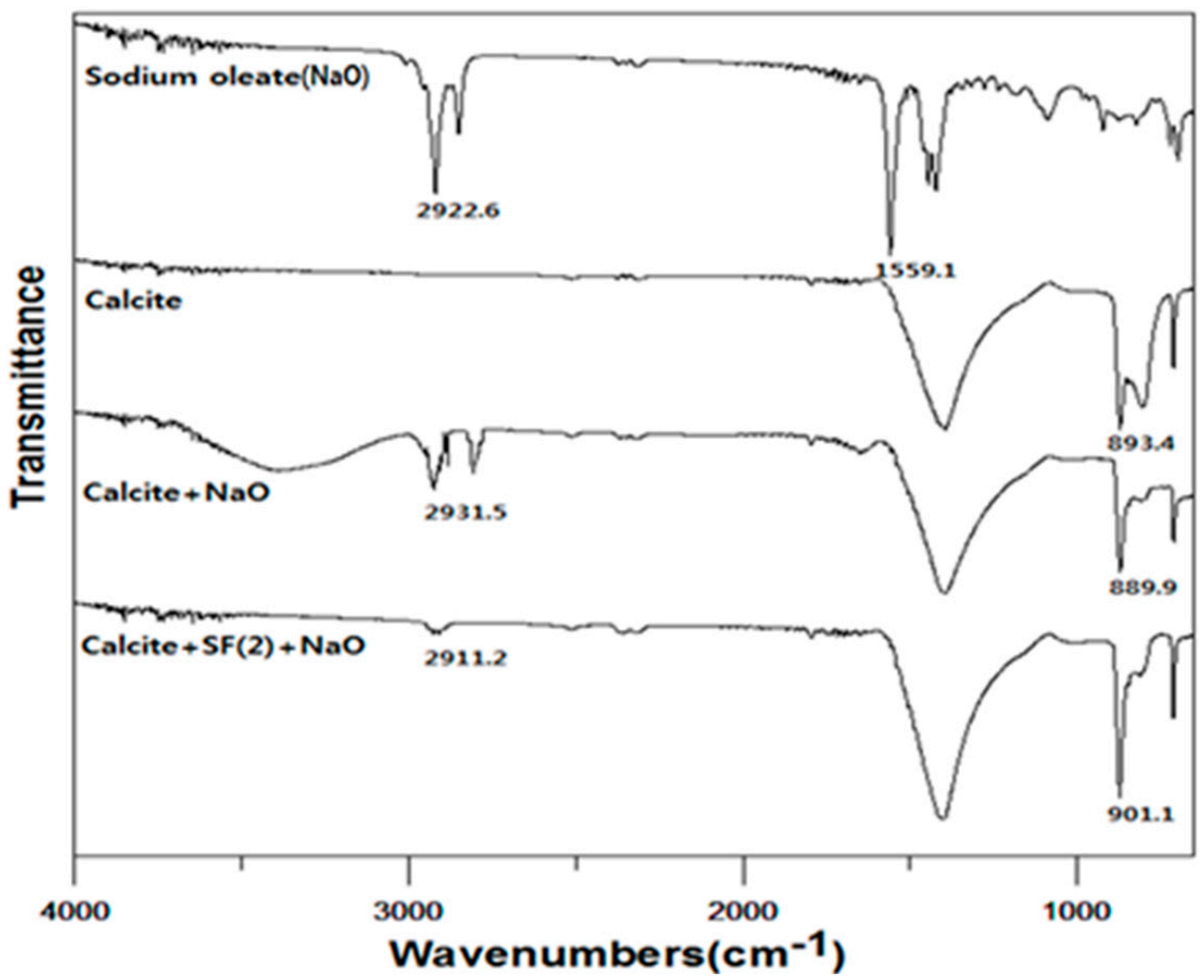

Figure 10. FTIR analysis result of calcite at the optimum flotation conditions. 


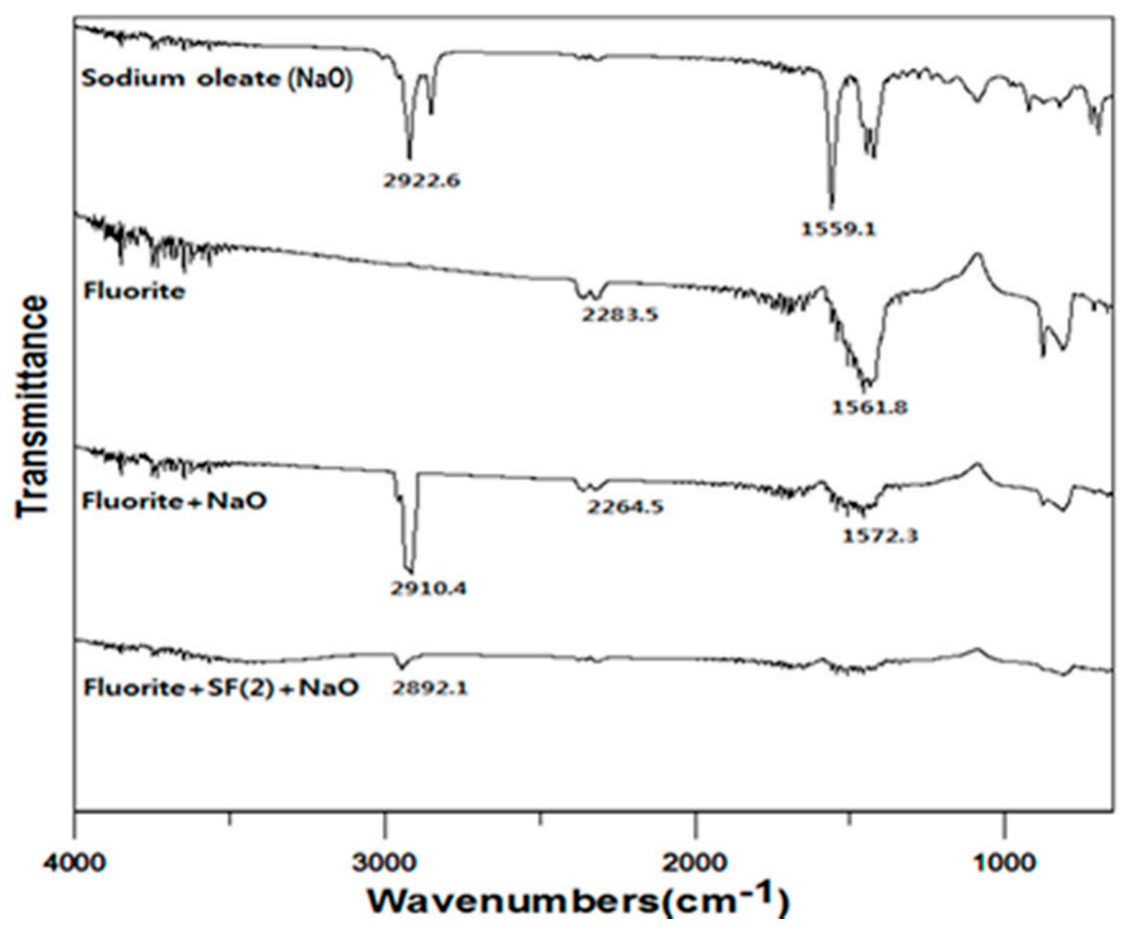

Figure 11. FTIR analysis result of fluorite at the optimum flotation conditions.

\section{Conclusions}

The addition of ferrous sulfate as a depressant for Ca-bearing minerals such as calcite and fluorite during scheelite flotation was investigated using Hallimond-tube flotation tests, zeta-potential measurement and FT-IR analyses.

The flotation tests indicate that the selectivity of scheelite recovery was the largest over calcite and fluorite under the following conditions: $0.5 \mathrm{~g}$ sample, $50 \mathrm{~g} / \mathrm{ton}$ AF65, $1 \times 10^{-3} \mathrm{M}$ sodium oleate, $1200 \mathrm{~g} /$ ton SF2 (sodium silicate and ferrous sulfate) depressant with the 8:2 ratio of sodium silicate and ferrous sulfate, $50 \mathrm{~mL} / \mathrm{min}$ air injection rate, $5 \mathrm{~min}$ flotation time, and $\mathrm{pH} 8$. The selectivity of scheelite flotation increased when the amount of SF2 depressant addition increased to $1200 \mathrm{~g} / \mathrm{ton}$, but it decreased by adding $1400 \mathrm{~g} /$ ton SF2, which would result from the precipitation of iron components.

In the zeta potential and Fourier-transform infrared (FTIR) analyses results of scheelite, calcite, and fluorite conditioned under the optimum conditions, the adsorption of $\mathrm{NaO}$ (collector) on the surface of scheelite was observed regardless of SF2 depressant addition, while the zeta potentials of calcite and fluorite and FT-IR spectra with $\mathrm{NaO} / \mathrm{SF} 2$ show similar behavior with calcite and fluorite without any floatation reagents. These results indicate that the addition of SF2 prevents the adsorption of $\mathrm{NaO}$ (collector) on the surface of calcite and fluorite, which are regarded as tailing during scheelite flotation, so the selectivity of scheelite flotation could be enhanced by adding the depressant consisting of sodium silicate and ferrous sulfate.

Author Contributions: Methodology, M.Y.J. and J.H.P.; writing-original draft preparation, M.Y.J. and K.Y.; project administration and funding acquisition, M.Y.J. and J.H.P.; data curation, M.Y.J. and K.Y.; writing-review and editing, providing ideas, M.Y.J., J.H.P. and K.Y. All authors have read and agreed to the published version of the manuscript.

Funding: This study was carried out as a research project for the "Establishment of $\mathrm{WO}_{3}$ flotation concentration conditions in tungsten tailings" of Mineral Reclamation Corporation in 2015. The authors would like to express their sincere gratitude for the support given by such corporation.

Conflicts of Interest: The authors declare no conflict of interest. 


\section{References}

1. Nguyen, T.T.; Yoo, K.; Jha, M.K.; Park, J.; Choi, U.; Choe, H.; Lee, J.C. Removal of Heavy Metals from Tailing in Citrate Solution with Ferric Chloride. Mater. Trans. 2018, 59, 1665-1668. [CrossRef]

2. Chu, Y.S.; Seo, S.G.; Choi, S.B.; Kim, G.M.; Hong, S.H. Properties of Cement Mortar as Particle Size and Hydrothermal Synthesis Temperature Using Scheelite Tailing. J. Korean Inst. Resour. Recycl. 2019, 28, 46-53. [CrossRef]

3. Kim, M.S.; Kang, H.C. A Study on Mineralogical Characterizations of Sangdong Mine Tailings. J. Korean Soc. Miner. Energy Resour. Eng. 2014, 51, 829-834. [CrossRef]

4. Yang, I.; Ji, W.; Park, J. Strategic investigation of development of mine reclamation technology based on third-stage road map. J. Korean Soc. Miner. Energy Resour. Eng. 2018, 55, 538-545. [CrossRef]

5. Ahn, H.H.; Lee, M.S. Hydrometallurgical Processes for the Recovery of Tungsten from Ores and Secondary Resources. J. Korean Inst. Resour. Recycl. 2018, 27, 3-10. [CrossRef]

6. Ilhan, S.; Kalpakli, A.O.; Kahruman, C.; Yusufoglu, I. The investigation of dissolution behavior of gangue materials during the dissolution of scheelite concentrate in oxalic acid solution. Hydrometallurgy 2013, 136, 15-26. [CrossRef]

7. Rao, K.H.; Forssberg, K.S.E. Mechanism of oleate interaction on salt-type minerals Part III. Adsorption, zeta potential and diffuse reflectance FT-IR studies of scheelite in the presence of sodium oleate. Colloids Surf. 1991, 54, 161-187. [CrossRef]

8. Baek, S.H.; Jeon, H.S. Application of Jig Separation for Pre-Concentration of Low-Grade Scheelite Ore. Mater. Trans. 2018, 59, 494-498. [CrossRef]

9. Kupka, N.; Rudolph, M. Froth flotation of scheelite-A review. Int. J. Min. Sci. Techno. 2018, 28, 373-384. [CrossRef]

10. Hu, Y.; Gao, Z.; Sun, W.; Liu, X. Anisotropic surface energies and adsorption behaviors of scheelite crystal. Colloids Surf. A. 2012, 415, 439-448. [CrossRef]

11. Shepeta, E.D.; Samatova, L.A.; Kondratev, S.A. Kinetics of calcium minerals flotation from Scheelite-carbonate ores. J. Min. Sci. 2012, 48, 746-753. [CrossRef]

12. Hu, Y.H.; Yang, F.; Sun, W. The flotation separation of scheelite from calcite using a quaternary ammonium salt as collector. Miner. Eng. 2011, 24, 82-84. [CrossRef]

13. Ozcan, O.; Bulutcu, A.N. Electrokinetic, infrared and flotation studies of scheelite and calcite with oxine, alkyl oxine, oleoyl sarcosine and quebracho. Int. J. Miner. Process. 1993, 39, 275-290. [CrossRef]

14. Gao, Z.; Bai, D.; Sun, W.; Cao, X.; Hu, Y. Selective flotation of scheelite from calcite and fluorite using a collector mixture. Miner. Eng. 2015, 72, 23-26. [CrossRef]

15. Deng, R.; Yang, X.; Hu, Y.; Ku, J.; Zuo, W.; Ma, Y. Effect of Fe (II) as assistant depressant on flotation separation of scheelite from calcite. Miner. Eng. 2018, 118, 133-140. [CrossRef]

16. Hu, Y.; Huang, Y.; Deng, R.; Ma, L.; Yin, W. Improvement Effect of FeSO4. 7H2O on Flotation Separation of Scheelite from Fluorite. ACS Omega. 2019, 4, 11364-11371. [CrossRef]

17. Bo, F.; Xianping, L.; Jinqing, W.; Pengcheng, W. The flotation separation of scheelite from calcite using acidified sodium silicate as depressant. Miner. Eng. 2015, 80, 45-49. [CrossRef]

18. Na, H.; Eom, Y.; Hong, S.; Yoo, K. The Effects of Iron Powder Agglomeration on the Copper Removal Efficiency during Cementation Process for Treating Mine Drainages. J. Korean Inst. Resour. Recycl. 2019, 28, 74-79. [CrossRef]

19. $\mathrm{Hu}, \mathrm{Y}$; $\mathrm{Xu}, \mathrm{Z}$. Interactions of amphoteric amino phosphoric acids with calcium-containing minerals and selective flotation. Int. J. Miner. Process. 2003, 72, 87-94. [CrossRef]

20. Rao, K.H.; Forssberg, K.S.E. Mechanism of fatty acid adsorption in salt-type mineral flotation. Miner. Eng. 1991, 4, 879-890.

21. Roonasi, P.; Yang, X.; Holmgren, A. Competition between sodium oleate and sodium silicate for a silicate/oleate modified magnetite surface studied by in situ ATR-FTIR spectroscopy. J. Colloid Interf. Sci. 2010, 343, 546-552. [CrossRef] [PubMed]

(C) 2020 by the authors. Licensee MDPI, Basel, Switzerland. This article is an open access article distributed under the terms and conditions of the Creative Commons Attribution (CC BY) license (http://creativecommons.org/licenses/by/4.0/). 